\title{
Deformation of Forsterite Polycrystals at Mantle Pressure: Comparison with Fe- Bearing Olivine and the EfFect of IRON ON ITS PLASTICITY
}

\author{
Caroline Bollinger ${ }^{1}$, Sébastien Merkel* ${ }^{*}$ Patrick Cordier, Paul Raterron
}

Unité Matériaux Et Transformations (UMET), CNRS, Université Lille 1, F-59655 Villeneuve d'Ascq, France

*Corresponding author: sebastien.merkel@univ-lille1.fr

\begin{abstract}
The rheology of polycrystalline forsterite was investigated in the Deformation-DIA (D-DIA) using in-situ x-ray diffraction at pressure between 3.1 and $8.1 \mathrm{GPa}$, temperature in the 1373-1673 $\mathrm{K}$ range, and at steady-state strain rate ranging from $0.5 \times 10^{-5}$ to $5.5 \times 10^{-5} \mathrm{~s}^{-1}$. Microscopic observations of the run products show characteristic microstructures of the so-called "dislocation creep regime" in wet conditions. Based on the present data at $1473 \mathrm{~K}$, the pressure effect on forsterite plasticity is quantified using an activation volume $V_{F o}^{*}=12.1 \pm 3.0 \mathrm{~cm}^{3} \cdot \mathrm{mol}^{-1}$. A comparison between the strain rates of San Carlos olivine and forsterite specimens deformed together indicates that, at the experimental conditions, they compare with each other within less than half an order of magnitude. This comparison also allows for the determination of the stress exponent of forsterite of $n_{F o}=2.3 \pm$ 0.6. Our results, combined with data from the literature, indicate a clear trend of increasing stress exponent with Fe content in olivine.
\end{abstract}

Keywords: Olivine; Forsterite; Rheology; Aggregate; Dislocation creep; High pressure; D-DIA; Stress exponent; Activation volume 3

Submitted to Physics of the Earth and Planetary Interiors

$$
\text { April } 7^{\text {th }}, 2014
$$

Corrections

September $04^{\text {th }}, 2014$

\footnotetext{
${ }^{1}$ Present address : Bayerisches Geoinstitut, University of Bayreuth, 95440 Bayreuth, Germany $1 / 21$
} 


\section{INTRODUCTION}

Olivine $(\mathrm{Mg}, \mathrm{Fe})_{2} \mathrm{SiO}_{4}$ is the main constituent of the Earth's upper mantle and, more generally, of the mantle of terrestrial planets. As such, the rheology of olivine-bearing rocks is relevant for constraining the dynamics occurring within these bodies. Olivine rheology depends on multiple parameters. The effect of temperature $(T)$ and differential stress $(\sigma)$ have long been quantified (e.g., Bai and Kohlstedt, 1992; Hirth and Kohlstedt, 2003). More recently, it has also been shown that pressure $(P)$, within the range in Earth's upper mantle, has a significant influence on olivine deformation mechanisms (e.g., Bollinger et al., 2014 and references therein).

Composition, also, is an important parameter. At the scale of a rock, other components such as pyroxenes (e.g., Bystricky et al., 2006; Raterron et al., 2014) or small melt fractions (e.g., Hirth and Kohlstedt, 1996; Mei et al., 2002; Holtzman et al., 2003) can affect significantly the mechanical properties. At the microscopic scale, the plastic response of olivine is sensitive to the oxygen fugacity $\left(\mathrm{fO}_{2}\right)$, crystal hydroxyl content [OH] (e.g., Girard et al., 2013), and iron content (Hitchings et al., 1989; Katayama and Karato, 2008; Zhao et al., 2009; Nishihara et al., 2014). In the Earth's mantle, olivine Fe number (Fe\#) - the Fe/(Mg+Fe) atomic ratio - ranges between 4 and 13\% (Deer et al., 1992, p. 12). The Martian mantle is expected to be significantly richer in iron with Fe\# estimated between 20 and 25\% (e.g., Khan and Connolly, 2008; Ruedas et al., 2013). Among the few studies devoted to the influence of iron on the olivine rheological properties, fewer have addressed the influence of this parameter at $P>3 \mathrm{GPa}$ (Nishihara et al., 2014).

Here we report results from deformation experiments performed at $P$ and $T$ up to $8.1 \mathrm{GPa}$ and $1673 \mathrm{~K}$, respectively, on iron-free olivine polycrystals, i.e., pure forsterite (Fo100) aggregates. We then quantify the rheology of forsterite at mantle conditions. Finally, we analyze the effect of iron content on olivine plasticity by comparing forsterite and San Carlos olivine specimens deformed at identical conditions.

\section{EXPERIMENTAL DETAILS AND RUN PRODUCT MICROSTRUCTURES}

Deformation experiments were performed in the Deformation-DIA apparatus (D-DIA, Durham et al., 2002; Wang et al., 2003) at the X17B2 beamline of the National Synchrotron Light Source (Upton, NY, USA), at $P$ ranging from 3.1 to $8.1 \mathrm{GPa}, T$ in the range $1373-1673 \mathrm{~K}$ and at controlled strain rates $\dot{\varepsilon}$ ranging from $0.5 \times 10^{-5}$ to $5.5 \times 10^{-5} \mathrm{~s}^{-1}$ (Table 1). Bollinger et al. (2014) reported details on the experimental set up, data analysis, and results for olivine. The following section is hence limited to the most relevant information regarding the present results. 


\section{Starting material, run $a_{O p x}$ and $\mathrm{fO}_{2}$ conditions}

The forsterite starting material was prepared by crushing one gem quality single crystal of Fo100 in an alumina-mortar, grinding it to a fine-grained powder at the optical scale (average grain size $\sim 10 \mu \mathrm{m}$ ). The starting crystal was synthesized at room pressure by the Czochralski (CZ) process (e.g., Takei and Kobayashi, 1974). It was dry, i.e., no hydroxyls were detectable using Fourier's transform infrared spectroscopy (FTIR, see Raterron et al., 2007).

Specimens were loaded into the D-DIA deformation cell (Fig. 1) in between two machinable alumina end plugs, which become hard pistons at run conditions. Two types of experiments were performed. Runs \#65, \#68, \#69, \#70 were carried out with one sample of pure forsterite powder in the compression column. Runs \#80, \#81, \#82, \#87, \#88, \#89 and \#90 were performed with two powder samples, one of pure forsterite and one of San Carlos olivine atop one another, separated by a thin layer of alumina sandwiched in between Re foils. Both forsterite and olivine powders were mixed with a small fraction (5 wt.\%) of natural enstatite (En84Fs13Wo3) powder, in order to buffer the orthopyroxenes $(\mathrm{Opx})$ activity $\left(a_{\mathrm{Opx}}=1\right)$ and limit grain growth during the runs (McDonnell et al., 2000). Although Fe-Mg exchanges must have occurred during the runs, mostly at contacts between enstatite and forsterite grains, they were limited by the Fe-Mg interdiffusivity in enstatite which is lower than that in olivine (diffusion rates of $\sim 0.1 \mu \mathrm{m} /$ hour at $T=1673 \mathrm{~K}$, Ganguly and Tazzoli, 1994; Jaoul et al., 1995). Given the run temperatures, durations, the enstatite grain size (several microns) and small fraction, the amount of iron which can diffuse into forsterite grains during the runs is negligible, i.e., it cannot significantly affect the forsterite composition (Fo100).

The oxygen fugacity $\left(\mathrm{fO}_{2}\right)$ was not controlled during the runs. This is because encapsulating the specimens into metal/metal-oxide jackets reduces the accuracy of differential-stress $(\sigma)$ measurements by X-ray diffraction. Indeed, such capsules typically have a strong absorption coefficient in the 10-40 keV energy range of the X17B2 beamline. Moreover, the strong diffraction peaks from the metal jacket could hide essential information from material of interest. This is not an issue for forsterite for which rheology is essentially $\mathrm{fO}_{2}$ insensitive. Unlike forsterite, San Carlos olivine plasticity is sensitive to $\mathrm{fO}_{2}$ (e.g., Keefner et al., 2011). However, as reported in Bollinger et al. (2014), olivine run products do not exhibit silica-rich or metallic micro-precipitates related to oxidation or reduction, attesting that these samples remained within the olivine Redox stability field during deformation.

\section{In situ strain, pressure, differential stress and temperature measurements}

Specimen strain $(\varepsilon)$ and strain rate $(\dot{\varepsilon})$ were measured from the positions of metal foils placed at sample ends (Fig. 1) by time-resolved X-ray radiography (Vaughan et al., 2000). The distance 
between the foils was measured by eye at given horizontal positions on the radiographs and used as a proxy for specimen lengths. Beside the image pixel resolution, sources of uncertainties using this method are the possible rotation and/or thinning of the foils during deformation. However, significant rotations of the foils relative to the several percent specimen strains would have been detected visually. Using hard Re foils also prevents significant thinning of the strain markers during deformation. The obtained strain rates and corresponding uncertainties are reported in Table 1.

Taking advantage of the ten-element energy-dispersive multi-detector (Weidner et al., 2010), $P$ and $\sigma$ were measured in situ from $d$-spacing variations for given reflections in different orientations with respect to the principal stress directions. Following the protocol reported in Bollinger et al. (2012), alumina 012, 104, 110, 113, 024 and 116 first-order diffraction lines were used along with thermal expansion coefficients from Fei (1995), elastic moduli and thermal derivatives of Anderson and Isaak (1995), and the pressure derivatives of Duan et al. (1999). The calculation is based on a purely elastic model (Singh et al., 1998), which does not account for stress heterogeneities or relaxation induced by plastic deformation (Merkel et al., 2009). Consequently, different $\sigma$ values are obtained from different $h k l$ lines. More sophisticated approaches based on elasto-plastic self-consistent (EPSC) modeling can be used to measure more accurately the "true- $\sigma$ " and, in the case of alumina, Raterron et al. (2013) showed that averaging $h k /$-line stresses leads to reasonable estimates. Stresses reported in Table1 for the sample, top, and bottom pistons are hence calculated using a weighted mean of all $h k l$-line stresses for each. Errors on individual $h k l$-stresses are propagated to obtain a first source of error on the specimen mean stress (resulting from the accuracy of the measurement). We then calculate the standard deviation of all measured $h k l$-stresses for each specimen (error resulting from the physical model). In a conservative approach, we finally assume that the total error on $\sigma$ for each specimen is the sum of these two values.

Temperature was measured using two horizontal W3\%Re-W25\%Re thermocouples (no pressure correction) whose junctions were placed at the centre of the cell assembly (Fig. 1). Run $T$ uncertainty is mostly due to axial thermal gradients, which can be in excess of $\sim 150 \mathrm{~K} / \mathrm{mm}$ at high $T$ at the centre of the cell (Raterron et al., 2013). Given the present run nominal $T$, and the size and vertical position of our specimens, we estimate $T$ uncertainty to $\pm 100 \mathrm{~K}$.

Pressure was measured in the pistons using the parameters listed above. It was also measured in the forsterite specimens using 021, 101, 002, 130, 131, 112 and 041 diffraction lines and equation of state (EoS) parameters extracted from Isaak et al. (1989) and Zha et al. (1996). For each material, pressures reported in Table 1 are weighted mean values of all pressures measured during steady-state. When measuring the cell pressure in the pistons from an EoS, thermal axial gradients cannot be omitted (Raterron et al., 2013). Here, we assume that the specimen nominal $T$ was that 
measured (or previously calibrated) with the thermocouples, and that the pistons $T$ was $200 \mathrm{~K}$ lower. In some cases, we observe large $P$ gradients between the top of bottom pistons (e.g. run \#65). They could be due to the assumption that both pistons' diffraction volumes are at the same temperature. A $100 \mathrm{~K}$ error results in a $0.5 \mathrm{GPa}$ error on the calculated $P$ (Raterron et al., 2013). Do note, however, that larger $P$ gradients ( $1 \mathrm{GPa}$ or more) are often observed at $1373 \mathrm{~K}$, when the cell assembly can sustain such gradients.

\section{Deformation protocol}

We performed a total of 12 D-DIA experiments, resulting in 24 steady-state deformation conditions in axisymmetric compression (Table 1) and 1 in lateral compression during Run \#65. For each experiment, the cell is first pressurized at room $T$ then brought to high $T$. We then sinter the pistons and specimens and relax cold-compression stresses for $\sim 1$ hour at $1473 \mathrm{~K}$ in hydrostatic conditions. We then perform axisymmetric deformation by moving forward D-DIA vertical anvils at a fixed rate until $\varepsilon$ reaches $5-10 \%$ at constant $\dot{\varepsilon}$. Several $T$ and/or $\dot{\varepsilon}$ are usually tested during each experiment. At the end of the experiment, $T$ is quenched by turning off the power supply and both $D$ DIA vertical anvils are stopped. $P$ is then decreased for 1 to 2 hours to room $P$, while the specimen length is maintained constant by adjusting the vertical anvil positions.

\section{Run product hydroxyl contents}

The hydroxyl concentration $([\mathrm{OH}])$ of the deformed forsterite specimens was quantified by FTIR measurement (Fig. 2) using a Bruker Hyperion 3000 IR microscope equipped with a MCT nitrogen-cooled detector. Transmission unpolarized spectra were recorded from $\sim 0.2-0.4-\mathrm{mm}$ thick double-polished sections supported on a $\mathrm{CaF}_{2}$ disc. $[\mathrm{OH}]$ was estimated from the integral absorbance of the $\mathrm{OH}$ bands using the calibrations of Paterson (1982) and Bell et al. (2003) (Table 1). Values according to the calibration of Bell et al. (2003) were corrected by a factor $0.188 \times 3$ to account for our unpolarized measurements on polycrystals. Although no water was added when loading the cell assembly, the measured $[\mathrm{OH}]$ range between 110 and 1777 ppm H/Si (Paterson's calibration).The origin of the water is unknown and likely related to several sources, such as the presence of moisture in the cement used to hold the thermocouples within the boron-epoxy pressure medium (Fig. 1). Hydroxyl contents in excess of $2200 \mathrm{ppm} \mathrm{H/Si}$ has been previously measured in forsterite deformed at $11 \mathrm{GPa}$ pressure and $1673 \mathrm{~K}$ in nominally dry cell assembly (Couvy et al., 2004). Such hydroxyl contents, although significant, are low when compared to values reported for Fo100 at water saturated conditions, e.g., $14500 \mathrm{ppm} \mathrm{H/Si} \mathrm{at} 5.7 \mathrm{GPa}$ and $1448 \mathrm{~K}$ (Mosenfelder et al., 2006).

Girard et al. (2013) reported that, at high pressure, a few hundreds ppm H/Si lowers the flow stress of Fe-free and Fe-bearing olivine single-crystals by a factor of $\sim 1.5$. They also show that, once 
in the 'wet' conditions of deformation, olivine plasticity does not depend significantly on its hydroxyl content. We thus conclude that the present experiments were performed in 'wet' conditions of deformation. We also note that the hydroxyl contents measured here in forsterite run products are comparable to those measured in San Carlos olivine specimens after deformation in the same cell assembly (within 153 - 1526 ppm H/Si, Bollinger et al., 2014). Hence, the comparison of both materials rheology is appropriate for quantifying the effect of iron on olivine plasticity at high pressure (Section II).

\section{Run products deformation microstructures}

Thin sections ( $25 \mu \mathrm{m}$ thick) for transmission electron microscopy (TEM) were prepared from the central part of the deformed specimens. They were optically polished on both sides then ionthinned with a $5 \mathrm{kV}$ argon beam, before carbon coating. A Philips CM30 and a FEI Tecnai G2-20 Twin, operating at 300 and $200 \mathrm{kV}$, respectively, were used to investigate sample microstructures.

The microstructure of Run \#65 forsterite product - further called sample \#65 - deformed at $1373 \mathrm{~K}$ and $\sim 5.5 \mathrm{GPa}$, is illustrated Figures $3 \mathrm{a}$ and $3 \mathrm{~b}$. Grains with little internal contrasts vary in size from 0.5 to $3 \mu \mathrm{m}$. The microstructure exhibits numerous dislocations of either [001] or [100] Burgers vector gliding in (010) plane, as well as many regularly spaced $(c a .0 .7 \mu \mathrm{m})$ subgrain boundaries. The [001]-dislocation density is in the range $10-23 \times 10^{13} \mathrm{~m}^{-2}$ (Fig. 3a), very comparable to the density of [100]-dislocations: $25 \times 10^{13} \mathrm{~m}^{-2}$ (Fig. 3b). Dislocation microstructures are indicative of lattice friction, indicated by dislocations exhibiting straight segments and relatively confined in their glide planes (Figs. 3a and 3b), with cross-slip (indicated by the presence of open sessile loops) and climb (subgrain boundaries). (010) and $\{110\}$ have been identified as glide planes for [001]-dislocations. At $7.3 \mathrm{GPa}$ and $1673 \mathrm{~K}$ (sample \#88B) the grain size is larger $(3-5 \mu \mathrm{m})$. The deformation is heterogeneous from grain to grain. Again, regularly spaced (every $0.7 \mu \mathrm{m}$ ) and well-organized subgrain boundaries containing [001]-dislocations are observed (Fig. 3c, d) indicating that climb was active. We also observed [100]-dislocations (Fig. 3d). The average dislocation density $\left(1-3 \times 10^{13} \mathrm{~m}^{-2}\right)$ is lower than in sample \#65. [001]-dislocations are found to glide in both (100) and \{110\} planes. Above $1673 \mathrm{~K}$, grains are typically larger $(3$ to $5 \mu \mathrm{m})$ in average than at $1373 \mathrm{~K}(0.5$ to $3 \mu \mathrm{m})$ with lower dislocation densities indicative of recovery.

We conclude from these observations that deformation occurred in the so-called "dislocation creep regime", which here refers to the climb-assisted dislocation creep regime often identified in the case of large-grain olivine-aggregate plasticity at high temperature. In this deformation regime, most of the strain is produced by the observed glide of dislocations. Nevertheless, the occurrences of subgrain boundaries attest the activation of dislocation climb, which may control the the strain-rate. 
Do note, however, that this does not preclude the joint-activation of other mechanisms such as grain boundary sliding (Hirth and Kohlstedt, 1995) or disclinations (Cordier et al., 2014).

For some samples, the dislocation density was so high that individual dislocations, and even grain boundaries, could not be resolved (Fig. 4a). Such is the case of sample \#70 deformed at $3.1 \mathrm{GPa}, 1373 \mathrm{~K}$ and $4.5 \times 10^{-5} \mathrm{~s}^{-1}$ to $40 \%$ strain. To characterize the microstructure of those samples we used orientation mapping in the TEM (Rauch et al., 2008). Fig. 4b shows an orientation map performed at SIMAP, Grenoble (coll. M. Véron and E. Rauch) on sample \#70. Colours indicate the crystal orientation parallel to the electron beam. The orientation map allows the grains to be distinguished despite the large defect density. The distribution is bimodal in this highly deformed material, with grains 2 to $3 \mu \mathrm{m}$ in size surrounded by smaller grains of 0.2 to $0.5 \mu \mathrm{m}$.

\section{RHeological RESULtS}

\section{High pressure rheology formulation}

The high-temperature plasticity of mineral aggregates is usually analyzed in terms of a simple empirical power law such as (Poirier, 1985):

$$
\dot{\varepsilon}=A \sigma^{n} e^{-\left(H^{*} / R T\right)}
$$

Where $A$ and $n$ are constants, $R$ is the gas constant and $H^{*}$ the apparent activation enthalpy. This law can include pre-exponential terms to account for strain-rate sensitivities to the activity or the fugacity of given phases (e.g., $a_{\mathrm{Opx}}, f_{2}$ ) or a given impurity concentration (e.g.,[OH]). Eq. 1 exhibits the formalism of thermally activated phenomena at constant entropy. $H^{*}$ is thus often expressed as $H^{*}=E^{*}+P V^{*}$, where $E^{*}$ and $V^{*}$ are the apparent activation energy and volume, respectively. As discussed previously (Bollinger et al., 2014), such an analysis implies that $H^{*}$ varies linearly with $P$, an assumption not always verified given the complexity of mineral aggregate deformation. To avoid unnecessary assumptions, we use the reformulation proposed in Bollinger et al. (2014) where Eq. 1 is rewritten as:

$$
{ }^{P, T}=H^{*}(P)-R T \ln A=R T(n \ln \sigma-\ln \dot{\varepsilon})(2) .
$$

Values for the $H^{P, T}$ can be directly quantified from experimental $T, \sigma$ and $\dot{\varepsilon}$ values, assuming a given value for the stress exponent $n . H^{P, T}$ pressure dependence is that of the apparent enthalpy $H^{*}$ : if linear, a constant $V^{*}$ can be defined such as $H^{*}=E^{*}+P V^{*}$. If $H^{P, T}$ exhibits a more complex dependence on $P$, no $V^{*}$ can be defined and other parameterization should be used. Plotting $H^{P, T}$ vs. $P$ allows discriminating whether a single activation volume $V^{*}$ can be defined and quantified for a 
given dataset, with no assumption regarding the pre-exponential parameter $A$ and the activation energy $E^{*}$. It requires, however, knowing the material stress exponent $n$.

For olivine aggregate high- $T$ deformation in the dislocation creep regime, the value $n_{O l}=3.5$ quantified at low pressure $(P<3 \mathrm{GPa})$ is well accepted by the community (e.g., Hirth and Kohlstedt, 2003). No quantification of this parameter has been reported at high pressure. In the following, we rely on low- $P$ experiments and assume $n_{O l}=3.5$ for high- $P$ olivine deformation. Studies are scarce for forsterite (Fo100) aggregate high- $T$ dislocation creep- whether involving diffusion and/or grain boundary sliding (GBS) (Relandeau, 1981; McDonnell et al., 2000; Ji et al., 2001; Nishihara et al., 2014). The reported values for Fo100 stress exponent $\left(n_{F o}\right)$ exhibit large discrepancy, in the 1.3-2.8 range. In the next paragraph, we thus evaluate $n_{F O}$ from $n_{O l}$ by comparing the strain rates of forsterite and olivine specimens deformed together in the D-DIA compression column, i.e., at identical $P, T, \sigma$, and fluid fugacity.

\section{Forsterite stress exponent evaluation}

In some experiments, we placed two samples of San Carlos olivine and forsterite atop each other (Fig. 1). Both samples are then visible on the X-ray radiographs, allowing for measurements of relative strain and strain rates. Accurate determination of the applied differential stress $\sigma$ is not required as both materials experience the same stress environment. Figure 5, for instance, shows forsterite and olivine strain vs. time during Run \#81; constant slopes on this figure correspond to steady-state strain rates. An increase in differential stress at constant $P$ and $T$ (e.g., from 78 to $341 \mathrm{MPa}$ at $5 \mathrm{GPa}$ and $1573 \mathrm{~K}$ ) translates into a larger increment of strain rate in olivine than that in forsterite. The forsterite strain rate is hence less sensitive to stress than that of olivine, i.e., $n_{F o}<n_{O l}$.

If $\dot{\varepsilon}^{\mathrm{i}}$ and $\dot{\varepsilon}^{\mathrm{ii}}$ are two strain rates measured under two applied stresses $\sigma^{\mathrm{j}}$ and $\sigma^{\mathrm{ji}}$ at given $P$ and $T$ for a given specimen (forsterite or olivine), each strain rate and corresponding stress verify Eq. 1 and, hence,

$$
\left(\dot{\varepsilon}^{\mathrm{i}} / \dot{\varepsilon}^{\mathrm{ii}}\right)^{1 / \mathrm{n}}=\sigma^{\mathrm{i}} / \sigma^{\mathrm{ii}}
$$

Forsterite and olivine in the same column experience the same differential stress, i.e., share the same $\sigma / \sigma^{\mathrm{ii}}$ ratio. Therefore,

$$
\left(\dot{\varepsilon}_{F o}^{\mathrm{i}} / \dot{\varepsilon}_{F O}^{\mathrm{ii}}\right)^{1 / n_{\mathrm{Fo}}}=\left(\dot{\varepsilon}_{O l}^{\mathrm{i}} / \dot{\varepsilon}_{O l}^{\mathrm{ii}}\right)^{1 / n_{\mathrm{Ol}}}
$$

where $\dot{\varepsilon}_{F O}^{\mathrm{i}}$ and $\dot{\varepsilon}_{F O}^{\mathrm{ii}}$ are the two strain rates measured for forsterite, and $\dot{\varepsilon}_{O l}^{\mathrm{i}}$ and $\dot{\varepsilon}_{O l}^{\mathrm{ii}}$ are those for San Carlos olivine. Re-arranging Eq. 4, one obtains: 


$$
n_{F o}=n_{O l} \times\left(\ln \frac{\dot{\varepsilon}_{F O}^{\mathrm{i}}}{\dot{\varepsilon}_{F O}^{\mathrm{i}}} / \ln \frac{\dot{\varepsilon}_{O l}^{\mathrm{i}}}{\dot{\varepsilon}_{O l}^{\mathrm{ii}}}\right)
$$

Equation 5 allows $n_{F O}$ to be quantified assuming $n_{O l}=3.5$, using strain-rate couples measured at stable $P$ and $T$ and two different stress conditions. Our dataset for forsterite (this study) and olivine (Bollinger et al., 2014) allows for such an analysis at 4 points (Table 2). Errors in this analysis are large when $\dot{\varepsilon}^{\mathrm{i}}$ and $\dot{\varepsilon}^{\mathrm{ii}}$ values are close but, for large differences in strain rates, correct estimates of $n_{F o}$ can be obtained. For those reasons, 2 out of the 4 available data points show large errors and are not statistically significant. Finally, a weighted mean of all results in Table 2, mostly constrained by run $\# 81$, leads to $\left\langle n_{F o}\right\rangle=2.3 \pm 0.6$

\section{Effect of pressure on forsterite aggregate rheology}

Figure 6 shows $H^{P, T}$ vs. $P$ for the 24 data points obtained in compression at 1373, 1473, 1573, and $1673 \mathrm{~K}$ along with the results of Nishihara et al.(2014). Due to the large discrepancy in $n_{F o}$ reported in the literature, $H^{P, T}$ was calculated using $n_{F o}=1.7$ (open circles, McDonnell et al., 2000), $n_{F o}=2.3$ (full square, this study), and $n_{F o}=3.5$ (open diamond) for comparison with olivine. The grey areas on Figure 6 indicate the $H^{P, T}$ vs. $P$ fits reported for San Carlos olivine (Bollinger et al., 2014), corresponding to $n_{O l}=3.5 \quad$ and $V_{O l}^{*}=12.8 \pm 5 \mathrm{~cm}^{3} \cdot \mathrm{mol}^{-1}$. Data from Nishihara et al. (2014) were evaluated using $n_{F o}=1.9$, as suggested in their paper (open triangles).

The most precise results are obtained at $1473 \mathrm{~K}$. Assuming $n_{F o}=2.3, H^{P, T}$ is linear with $P$ and a linear least square fit to the data at $1473 \mathrm{~K}$ leads to $V_{F o}^{*}=12.1 \pm 3 \mathrm{~cm}^{3} \cdot \mathrm{mol}^{-1}$. This value is fairly independent of the choice of the stress exponent. Note that, with $n_{F o}=3.5$, the present $1473 \mathrm{~K}$ forsterite data falls within the grey area, i.e., are consistent with the San Carlos olivine data reported previously (Bollinger et al., 2014).

Given the constant $V_{F O}^{*}$ in Fig. 6 at $1473 \mathrm{~K}$, the intercept at $P=0$ reads (Eq. 2):

$$
H^{0, T}=E_{F o}^{*}-R T \ln A_{F o} \quad \text { (7) }
$$

where $E_{F o}^{*}$ and $A_{F o}$ are the forsterite activation energy and pre-exponential factor, respectively (Eq. 1). The least square fit to the data at $1473 \mathrm{~K}$ leads to $H^{0, T}=245 \pm 16 \mathrm{~kJ}^{\mathrm{mol}}{ }^{-1}$ (open square at $P=0$ ), assuming $n_{F o}=2.3$. For forsterite dislocation creep at room $P, E_{F o}^{*}=418 \mathrm{~kJ} \cdot \mathrm{mol}^{-1}$ (Relandeau, 1981) and, hence, we deduce that, for our experimental conditions, $\ln A_{F o}=(14.1 \pm 1.3) \cdot 10^{3} \mathrm{~mol}^{-1}$. We then calculate the intercept $H^{0, T}$ at $1373 \mathrm{~K}, 1573 \mathrm{~K}$ and $1673 \mathrm{~K}$ using Eq. 7 (Fig. 6, open squares and associated uncertainties). Assuming no change in deformation mechanisms with temperature, we use value of $V^{*}$ at $1473 \mathrm{~K}$ for estimating pressure effects at other 
temperatures (Fig. 6, solid lines and associated uncertainties, dashed lines) and comparing with our measurements.

Most data obtained at $\mathrm{T}>1473 \mathrm{~K}$ are consistent, within uncertainties, with the anchor values defined for the $1473 \mathrm{~K}$ dataset where a clear $P$ dependence is observed. At $1373 \mathrm{~K}$, data suggest a smaller value of $V^{*}$, although all but two points fall within the uncertainties of the fitted parameters to the $1473 \mathrm{~K}$ dataset. Overall, due to the large uncertainties in our measurements, a change of plastic behavior and, hence, activation volume of forsterite with temperature cannot be ruled out.

We thus conclude that the present forsterite data are consistently accounted for with a linear $P$ dependence with $H^{P, T}$ (Eq. 2). A constant activation volume $V_{F o}^{*}=12.1 \pm 3.0 \mathrm{~cm}^{3} \cdot \mathrm{mol}^{-1}$ quantifies the $P$ sensitivity of forsterite aggregate plasticity in the dislocation creep regime at $1473 \mathrm{~K}$ up to $8.1 \mathrm{GPa}$ and is consistent with measurements at other temperatures.

\section{DISCUSSION}

\section{Effect of iron content on the olivine creep rate}

Zhao et al. (2009) investigated the effect of olivine Fe\# on aggregate plasticity at $P=0.3 \mathrm{GPa}, T$ within $1273-1473 \mathrm{~K}$, and $\sigma$ within 50-300 MPa. They studied compositions ranging from $\mathrm{Fa} 30$ to $\mathrm{Fa} 100$, i.e., with Fe\# ranging from $30 \%$ to 100\%, and observed a significant weakening associated with increasing Fe\# with creep rates up to 1480 times faster for Fe rich compositions. In their interpretation, their rheological data result from dislocation-accommodated grain boundary sliding. Whether such strong effect extrapolates to high pressure is unclear, because of the lack of data at $P>3 \mathrm{GPa}$.

The ratios of San Carlos olivine vs. forsterite strain rates measured here for specimens deformed atop each other indicate that San Carlos olivine is slightly weaker than forsterite (Fig. 7). At the conditions of the experiment, San Carlos olivine and pure forsterite strain rates compare with each other within less than half an order of magnitude at all tested $P-T$ - $\sigma$ conditions. Hence, our data is incompatible with a consistent and significant weakening of olivine with increasing Fe\#.

\section{Stress sensitivity of olivine solid-solution plasticity}

The stress exponent we obtain for forsterite aggregates $-n_{F o}=2.3(6)-$ is remarkably consistent with $n_{F o}=2.5$ (6) obtained at room $P$ and $1673 \leq T \leq 1773 \mathrm{~K}$ by Relandeau (1981). Values < 2.0 have been reported in other experiments (McDonnell et al., 2000; Ji et al., 2001; Nishihara et al., 2014) but, in all cases, these low $n_{F o}$ values have been interpreted as resulting from dislocation-accommodated diffusion creep or grain boundary sliding (GBS). For single crystals, 
$n=2.6$ (2) and 2.7 (3) have been reported for the so-called $[110]_{\mathrm{c}}$ and $[011]_{\mathrm{c}}$ directions while $n=3.6$ (3) was reported along $[101]_{c}$ direction (Darot and Gueguen, 1981). This [101 $]_{c}$ orientation activates the [100](001) and [001](100) systems together. The activity of these systems may be limited in experiments at high pressure (Raterron et al., 2012). We thus conclude that the strain rate sensitivity of forsterite aggregate (Fo100) deforming in the dislocation creep regime is well constrained using $n_{F o}=2.3 \pm 0.6$. Do note, however, that this determination is essentially controlled by two experimental measurements. High pressure experiments do not allow duplicating multiple data points easily and this trend will have to be confirmed in the future.

This $n_{F o}$ value - which applies to the plasticity of dry or moderately 'wet' polycrystalline forsterite - is significantly lower than the accepted value for dry or 'wet' San-Carlos olivine (Fo90) deforming in the dislocation creep regime $\left(n_{O l}=3.5 \pm 0.3\right.$, Hirth and Kohlstedt, 2003). Dislocation glide-controlled creep is usually associated with the typical stress exponent $n=3$, which is elegantly explained by the micromechanical model proposed by Weertman (1970). Weertman and Weertman (1975) extended this model to climb-controlled dislocation creep, leading to stress exponents $\geq 3$ (up to $n=4.5$ ). This model, however, cannot explain values of $n<3$, as observed for forsterite. This illustrates the limit of ad-hoc micromechanical modeling when addressing the complexity of mantle mineral plasticity.

Chemical differences between pure forsterite and San Carlos olivine probably explain the significant difference between both compounds stress sensitivity. Indeed, the stress exponents of olivine increases with Fe\# (Fig. 8), with values reaching up to 4.7 (1) for dry Fe-rich olivine (fayalite, with Fe\# $\geq 50 \%$ ) deformed at $P=0.3 \mathrm{GPa}$ and $T$ in the $1273-1474 \mathrm{~K}$ range (Zhao et al., 2009). There is a positive correlation between olivine solid-solution iron content and the sensitivity to stress of its plastic response in the dislocation creep/dislocation-accommodated GBS regime.

This observation concerns deformation regimes where intracrystalline dislocation motions play a critical role. We speculate that its explanation may lie in changes with either the lattice friction associated with dislocation glide or the ionic diffusivity associated to dislocation climb with changing Fe content. More work is needed to clarify this point.

\section{Pressure sensitivity of olivine solid-solution}

The activation volume $V_{F o}^{*}=12.1 \pm 3.0 \mathrm{~cm}^{3} \cdot \mathrm{mol}^{-1}$ we obtain for forsterite aggregate high$T$ deformation in the dislocation creep regime is virtually identical to that reported for San Carlos olivine deformed in the same conditions $\left(V_{O l}^{*}=12.8 \pm 5.0 \mathrm{~cm}^{3} \cdot \mathrm{mol}^{-1}\right.$, Bollinger et al., 2014). In a recent paper, Nishihara et al. (2014) investigate the high pressure plasticity of fine grained forsterite aggregates at $1573 \mathrm{~K}$. A global fit through their dataset leads to $V_{F o}^{*}=11.2 \pm 2.6 \mathrm{~cm}^{3} \cdot \mathrm{mol}^{-1}$. Within errors, this value is consistent with our measurements. 
Moreover, the plot of their data obtained at $1573 \mathrm{~K}$ on Fig. 6 is remarkably consistent with the range of estimates for $H^{P, T}$ based on our own measurements.

Our values of activation volume for olivine and forsterite are also consistent with recent reports for 'dry' San Carlos olivine at high pressure: $V_{O l}^{*}=9.5 \pm 7.0 \mathrm{~cm}^{3} \cdot \mathrm{mol}^{-1}$ for experiments at $P$ reaching $5 \mathrm{GPa}$ (Durham et al., 2009) and $V_{O l}^{*}=15 \pm 3 \mathrm{~cm}^{3}$. $\mathrm{mol}^{-1}$ up to $9 \mathrm{GPa}$ (Dixon et al., 2012). They are also in good agreement with $V^{*}$ values reported for the deformation along the $[110]_{c}$ direction of 'dry' Fo100 and olivine single crystals: $V^{*}=15 \pm 3$ and $12 \pm 4 \mathrm{~cm}^{3} \cdot \mathrm{mol}^{-1}$, respectively (Raterron et al., 2009, 2011), and 'wet' olivine crystals $\left(V^{*}\right.$ within $12-17 \mathrm{~cm}^{3} \cdot \mathrm{mol}^{-1}$, Girard et al., 2013); this crystal orientation is the weakest in the $P$ and $T$ ranges of the present experiments. Activation volumes for 'dry' Fo100 and San Carlos olivine single crystals deformed along [101]c direction are lower $\left(V^{*}=9 \pm 2\right.$ and $11 \pm 5 \mathrm{~cm}^{3} \cdot \mathrm{mol}^{-1}$, respectively); this crystal orientation is the second weakest at high $T$ and $P<8 \mathrm{GPa}$. Finally, much lower activation volumes (typically in the range $0-3 \mathrm{~cm}^{3} \cdot \mathrm{mol}^{-1}$ ) are reported for crystals deformed at high- $T$ along $[011]_{\mathrm{c}}$ direction, i.e., for the [001](010) dislocation slip system, but this latter system is weakly activated at $P<8 \mathrm{GPa}$ (a review in Raterron et al., 2012).

We thus conclude that the activation volume $V_{F o}^{*}$ reported here is well representative of the high- $T$ plasticity of 'dry' and 'wet' forsterite aggregate in the dislocation creep regime, to pressure up to $8 \mathrm{GPa}$. Within experimental uncertainties, no effect of different iron contents on this activation volume can be observed.

\section{CONCLUSION}

Steady-state deformation experiments were performed in the D-DIA coupled with synchrotron radiation on polycrystalline forsterite at $P-T$ conditions representative of upper-mantle geotherms down to depths of $\sim 250 \mathrm{~km}$ (P,T-range from 3.8 to $8.1 \mathrm{GPa}$ and from 1373 to $1673 \mathrm{~K}$, respectively). Assuming a stress exponent $n_{O l}=3.5$ for San Carlos olivine, a comparison between strain rates measured in forsterite and San Carlos olivine in the same assembly leads to $n_{F o}=2.3 \pm$ 0.6. Such comparison also indicates that, at the conditions of the present experiments, San Carlos olivine is weaker than pure forsterite, within less than half an order of magnitude on the strain rate.

The present results, combined with data from the literature on other compositions, indicate a clear trend of increasing stress exponent with Fe content in olivine, from $n=2.3 \pm 0.6$ in the Fefree phase, up to $n=4.7 \pm 0.1$ for dry Fe-rich olivine (fayalite, with Fe\# $\geq 50 \%$ ). This observation concerns deformation regimes where intracrystalline dislocation motions play a critical role. We thus speculate that its explanation may lie in changes in either the lattice friction associated with dislocation glide or the ionic diffusivity associated to dislocation climb with changing iron content. 
At $1473 \mathrm{~K}$, the apparent activation enthalpy $H^{*}$ is linear with $P$ and $V_{F o}^{*}=12.1 \pm$ $3.0 \mathrm{~cm}^{3} \cdot \mathrm{mol}^{-1}$. This value is consistent with our measurements at other temperatures and those of Nishihara et al. (2014) at 1573K. This value is also consistent with recent measurements on San Carlos olivine (Bollinger et al., 2014 and references therein). We hence do not observe any effect of different iron contents on the activation volume of olivine.

\section{ACKNOWLEDGEMENTS}

The authors thank Pamela Burnley and two anonymous reviewers whose comments improved the manuscript, Takaya Nagaï (Osaka University) who kindly provided the Fo100 starting material, Hayian Chen (Stony Brook University), Jennifer Girard (Florida International University) and Caleb Holyoke (Texas A\&M University) for their assistance at the NSLS X17B2 beamline, Jannick Ingrin for his help with FTIR data collection and treatment, and Edgar Rauch and Muriel Véron (SiMAP, Grenoble) for performing the orientation mapping. The infrared measurements have been performed at the Laboratory of Infrared and Raman Spectrochemistry (LASIR) at the Université Lille 1. This research was supported by the Consortium for Materials Properties Research in Earth Sciences (COMPRES) under NSF Cooperative Agreement EAR 06-49658, as well as the Agence Nationale de la Recherche (ANR) Grant BLAN08-2_343541 "Mantle Rheology". The TEM national facility in Lille (France) is supported by the Conseil Regional du Nord-Pas-de-Calais, the European Regional Development Fund (ERDF), and the Institut National des Sciences de l'Univers (INSU, CNRS). Use of the National Synchrotron Light Source, Brookhaven National Laboratory, was supported by the U.S. Department of Energy, Office of Science, Office of Basic Energy Sciences, under Contract No. DE-AC02-98CH10886.

Anderson, O.L., Isaak, D.G., 1995. Elastic constants of mantle minerals at high temperature, In: A handbook of physical constants, Mineral Physics \& Crystallography, T.J. Ahrens, 64-97. AGU, Washington, DC.

Bai, Q., Kohlstedt, D.L., 1992. High-temperature creep of olivine single crystals, 2. Dislocation structures. Tectonophysics 206, 1-29.

Bell, D.R., Rossman, G.R., Maldener, J., Endisch, D., Rauch, F., 2003. Hydroxide in olivine: A quantitative determination of the absolute amount and calibration of the IR spectrum. J. Geophys. Res. 108 (B2), 2105.

Bollinger, C., Merkel, S., Raterron, P., 2012. In situ quantitative analysis of stress and texture development in forsterite aggregates deformed at 6 GPa and 1373 K. J. Appl .Crystallogr. 45 (2), 263-271. 
Bollinger, C., Raterron, P., Cordier, P., Merkel, S., 2014. Polycrystalline olivine rheology in dislocation creep: Revisiting experimental data to $8.1 \mathrm{GPa}$. Phys. Earth Planet. Inter. 228, 211-219

Bystricky, M., Heidelbach, F., Mackwell, S., 2006. Large-strain deformation and strain partitioning in polyphase rocks: Dislocation creep of olivine-magnesiowüstite aggregates. Tectonophysics 427, 115-132.

Cordier, P., Demouchy, S., Beausir, B., Taupin, V., Barou, F., Fressengeas, C., 2014. Dislinations provide the missing mechanism for deforming olivine-rich rocks in the mantle. Nature 507, 51-56.

Couvy, H., Frost, D.J., Heidelbach, F., Nyilas, K., Ungár, T., Mackwell, S., Cordier, P., 2004. Shear deformation experiments of forsterite at $11 \mathrm{GPa}-1400^{\circ} \mathrm{C}$ in the multianvil apparatus. Eur. J. Mineral. 16 (6), 877-889.

Darot, M., Gueguen, Y., 1981. High-temperature creep of forsterite single crystals. J. Geophys. Res. 86, 62196234.

Deer, W.A., Howie, R.A., Zussman, J., 1992. An Introduction to the Rock-forming Minerals, 2nd ed. Longman Scientific \& Technical, UK, with John Wiley \& Sons,NewYork, pp. 696.

Dixon, N., Durham, W.B., Kohlstedt, D.L., Mei, S., Xu, L., 2012. Measurement of activation volume for creep of anhydrous olivine at upper mantle pressures, AGU Fall meeting, San Francisco.

Duan, W., Karki, B.B., Wentzcovitch, R.M., 1999. High-pressure elasticity of alumina studied by first principles. Am. Mineral. 84 (11-12), 1961-1966.

Durham, W.B., Weidner, D.J., Karato, S.-I., Wang, Y., 2002. New Developments in Deformation Experiments at High Pressure. Rev. Mineral. Geochem. 51 (1), 21-49.

Durham, W., Mei, S., Kohlstedt, D.L., Wang, L., Dixon, N., 2009. New measurements of activation volume in olivine under anhydrous conditions. Phys. Earth Planet. Inter. 172 (1-2), 67-73.

Fei, Y., 1995. Thermal expansion in Mineral Physics and Crystallography, A handbook of physical constants. Ahrens, T.J., AGU (2), 29-44, Washington, D.C.

Ganguly, J., Tazzoli, V., 1994. Fe (super 2+) - Mg interdiffusion in orthopyroxene; retrieval from the data on intracrystalline exchange reaction. Am. Mineral. 79, 930-937.

Girard, J., Chen, J., Raterron, P., Holyoke, C.W., 2013. Hydrolytic weakening of olivine at mantle pressure: Evidence of [100](010) slip system softening from single-crystal deformation experiments. Phys. Earth Planet. Inter. 216, 12-20.

Hirth, G., Kohlstedt, D. L., 1995. Experimental constraints on the dynamics of the partially molten uppermantle. 2. Deformation in the dislocation creep regime. J. Geophys. Res. 100 (B8), 15441-15449.

Hirth, G., Kohlstedt, D.L., 1996. Water in the oceanic upper mantle: implications for rheology, melt extraction and the evolution of the lithosphere. Earth Planet. Sci. Lett. 144, 93-108.

Hirth, G., Kohlstedt, D.L., 2003. Rheology of the upper mantle and the mantle wedge: a view from the experimentalists, in: Inside the Subduction Factory, Geophys. Monogr. Ser. 138, J. Eiler (Ed.), AGU, Washington, D. C., pp. 83-105.

Hitchings, R.S., Paterson, M.S., Bitmead, J., 1989. Effect of Iron and Magnetite additions in olivine pyroxene rheology. Phys. Earth Planet. Inter. 55, 277-291.

Holtzman, B.K., Kohlstedt, D.L., Zimmernan, M., Heidelbach, F., Hiraga, T., Hustoft, J.W., 2003. Melt Segregation and Strain Partitioning: Implications for Seismic Anisotropy and Mantle Flow. Science 301, 1227-1229.

Isaak, D.G., Anderson, O.L., Goto, T., Suzuki, I., 1989. Elasticity of single-crystal forsterite measured to 1700 K. J. Geophys. Res. 94, 5895-5906. 
Jaoul, O., Bertranalvarez, Y., Liebermann, R.C., Price, G.D., 1995. Fe-Mg interdiffusion in Olivine up to 9GPa at $\mathrm{T}=600-900^{\circ} \mathrm{C}$ - Experimental data and comparison with defect calculations. Phys. Earth Planet. Inter. 89, 199-218.

Ji, S.C., Wang, Z.C., Wirth, R., 2001. Bulk flow strength of forsterite-enstatite composites as a function of forsterite content. Tectonophysics 341, 69-93.

Katayama, I., Karato, S.-I., 2008. Effects of water and iron content on the rheological contrast between garnet and olivine. Phys. Earth and Planet. Inter. 166, 57-66.

Keefner, J.W., Mackwell, S.J., Kohlstedt, D.L., Heidelbach, F., 2011. Dependence of dislocation creep of dunite on oxygen fugacity: Implications for viscosity variations in Earth's mantle. J. Geophys. Res. 116, B05201.

Khan, A., Connolly, J.A.D., 2008. Constraining the composition and thermal state of Mars from inversion of geophysical data. J. Geophys. Res. 113, E07003.

McDonnell, R.D., Peach, C.J., van Roermund, H.L.M., Spiers, C.J., 2000. Effect of varying enstatite content on the deformation behavior of fine-grained synthetic peridotite under wet conditions. J. Geophys. Res. B: Solid Earth 105, 13535-13553.

Mei, S., Bai, W., Hiraga, T., Kohlstedt, D.L., 2002. Influence of melt on the creep behavior of olivine-basalt aggregates under hydrous conditions. Earth Planet. Sci. Lett. 201, 491-507.

Merkel, S., Tomé, C., Wenk, H.R., 2009. Modeling analysis of the influence of plasticity on high pressure deformation of hcp-Co. Phys. Rev. B 79, 064110.

Mosenfelder, J.L., Deligne, N., Asimow, P.D., Rossman, G.R., 2006. Hydrogen incorporation in olivine from 2-12 GPa. Am. Mineral. 91 (2-3), 285-294.

Nishihara, Y., Ohuchi, T., Kawazoe, T., Spengler, D., Tasaka, M., Kikegawa, T., Suzuki, A.M., Ohtani, E., 2014. Rheology of fine-grained forsterite aggregate at deep upper mantle conditions. J. Geophys. Res.: Solid Earth 119 (1), 253-273.

Paterson, M.S., 1982. The determination of hydroxyl by infrared absorption in quartz, silicate glasses and similar materials. Bull. Mineral. 105, 20-29.

Poirier, J.P., 1985. High-temperature deformation processes in metals, ceramics and minerals, in: Creep of crystals, Cambridge Earth Science Series, Cambridge, University Press, Cambridge, U.K., (p. 76-93).

Raterron, P., Chen, J., Li, L., Weidner, D., Cordier, P., 2007. Pressure-induced slip-system transition in forsterite: Single-crystal rheological properties at mantle pressure and temperature. Am. Mineral. 92 (8-9), 14361445.

Raterron, P., Amiguet, E., Chen, J., Li, L., Cordier, P., 2009. Experimental deformation of olivine single crystals at mantle pressures and temperatures. Phys. Earth Planet. Inter. 172 (1-2), 74-83.

Raterron, P., Chen, J., Geenen, T., Girard, J., 2011. Pressure effect on forsterite dislocation slip systems: Implications for upper-mantle LPO and low viscosity zone. Phys. Earth Planet. Inter. 188 (1-2), 26-36.

Raterron, P., Girard, J., Chen, J., 2012. Activities of olivine slip systems in the upper mantle. Phys. Earth Planet. Inter. 200-201, 105-112.

Raterron, P., Merkel, S., Holyoke, C., 2013. Axial Temperature Gradient and Stress Measurements in the D-DIA Cell Using Alumina Pistons. Rev. Sci. Instrum. 84, 043906. 
Raterron, P., Detrez, F., Castelnau, O., Bollinger, C., Cordier, P., Merkel, S., 2014. Multiscale modeling of upper mantle plasticity: From single-crystal rheology to multiphase aggregate deformation. Phys. Earth Planet. Inter. 228, 232-243.

Rauch, E.F., Veron, M., Portillo, J., Bultreys, D., Maniette, Y., Nicolopoulos, S., 2008. Automatic Crystal Orientation and Phase Mapping in TEM by Precession Diffraction. Microscopy and Analysis Nanotechnology Supplement Nov. 2008.

Relandeau, C., 1981. High temperature creep of forsterite polycrystalline aggregates. Geophys. Res. Lett. 8, 733-736.

Ruedas, T., Tackley, P.J., Solomon, S.C., 2013. Thermal and compositional evolution of the Martian mantle: Effects of phase transitions and melting. Phys. Earth Planet. Int. 216, 32-58.

Singh, A.K., Balasingh, C., Mao, H.-K., Hemley, R.J., Shu, J., 1998. Analysis of lattice strains measured under nonhydrostatic pressure. J. Appl. Phys. 83 (12), 7567-7575.

Takei, H., Kobayashi, T., 1974. Growth and properties of Mg2SiO4 single crystals. J. Crystal Growth 23, 121-124.

Vaughan, M., Chen, J., Li, L., Weidner, D., Li, B., 2000. Use of X-ray Imaging Techniques at High Pressure and Temperature for Strain Measurements. Universities Press, Hyderabad, India 17th Airapt Conference: Science and Technology of High Pressure, 1097-1098.

Wang, Y., Durham, W.B., Getting, I.C., Weidner, D.J., 2003. The deformation-DIA: A new apparatus for high temperature triaxial deformation to pressures up to 15 GPa. Rev. Sci. Instrum. 74 (6), 3002.

Weertman, J., 1970. The creep strength of the Earth's mantle. Rev. Geophys. 8 (1), 145-168.

Weertman, J., Weertman, J.R., 1975. High Temperatue Creep of Rock and Mantle Viscosity. Annu. Rev. Earth Planet. Sci. 3, 293.

Weidner, D.J., Vaughan, M.T., Wang, L., Long, H., Li, L., Dixon, N.A., Durham, W.B., 2010. Precise stress measurements with white synchrotron x rays. Rev. Sci. Instrum. 81 (1), 013903.

Zha, C.-S., Duffy, T.S., Downs, R.T., Mao, H.-K., Hemley, R.J., 1996. Sound velocity and elasticity of single-crystal forsterite to $16 \mathrm{GPa}$. J. Geophys. Res. 101, 17535-17545.

Zhao, Y.H., Zimmerman, M.E., Kohlstedt, D.L., 2009. Effect of iron content on the creep behavior of olivine: 1. Anhydrous conditions. Earth Planet. Sci. Lett. 287, 229-240. 
Fig. 1: Cross-section of the cell assembly used for the experiments. Olivine and forsterite samples, separated by an alumina buffer, are studied simultaneously. Tc1 and Tc2 are thermocouples in contact with the alumina. Re foils are used to monitor samples strain using $x$-ray radiography. This paper focuses on forsterite rheology. Results regarding olivine rheology have been published in Bollinger et al. (2014).

Fig 2: Unpolarized FTIR spectrum for forsterite run products, normalized to a 1-cm sample thickness, after manually subtracting the baseline. Some samples (e.g. run\# 65, 81, 88, 90) contain a substantial amount of water. Other samples (e.g. run 70,89) are less hydrated. In any cases, our samples are not dry and hence, treated as 'wet' forsterite.

Fig. 3: TEM micrographs in Weak-Beam Dark Field (WBDF). (a) Sample \#65 (3-steps deformation experiment, $5 \mathrm{GPa}, 1373 \mathrm{~K}$ ). On this image performed with g: 004, one can see free [001]-dislocations in glide configuration in (010) plane. (b) Sample \#65, g: 400; [100]-dislocations with their screw and edge components gliding in the (010) plane. (c) Sample \#88B ( 7.3 GPa, 1473-1673 K); g: 004; [001]-dislocations. Many are involved in subgrain boundaries. (d) Same area with g=11-2. Both [100]- and [001]-dislocations are visible.

Fig. 4: a) Sample 70 (1373 K, $2.4 \mathrm{GPa}, 40 \%$ total deformation rate) observed in bright field. The high density of defects prevents observation of the microstructure, including grain sizes. b) Orientation map for sample 70 with corresponding color code, which is an inverse pole figure describing the crystal orientation perpendicular to the plane of view.

Fig. 5: Strain versus time for olivine (circle) and forsterite (squares) specimens deformed simultaneously during Run \#81 under the same conditions of $P, T$, and $\sigma$. Solid lines are linear fit through the data for extracting the steady-state strain rates, indicated in the figure. Note that strains in forsterite are lower than those in olivine, indicating the larger strength of forsterite relative to that of olivine. Also note that the olivine strain-rate sensitivity to stress is higher than that of forsterite (e.g. between steps 3 and 4). See text for further explanations.

Fig 6: ${ }_{H}^{P,}{ }^{T}=R T(n \ln \sigma-\ln \dot{\varepsilon})$ vs. $P$ for wet forsterite polycrystals for the four experimental temperatures of this study $(1373,1473,1573$ and $1673 \mathrm{~K})$. Open circles, solid squares, and open diamonds are data from this study assuming $n_{F o}=1.7$ (McDonnell et al., 2000), $n_{F o}=2.3$ (this study), and $n_{F o}=3,5$ (olivine, Hirth and Kohlstedt, 2003). Open triangles are data from Nishihara et al (2014), assuming $n_{F o}=1.9$. Solid and dashed lines at $1473 \mathrm{~K}$ is a fit to our data, assuming $n_{F o}=2.3$, and leading to $V^{*}=12.1 \pm 3.0 \mathrm{~cm}^{3} \cdot \mathrm{mol}^{1}$. Open square at $1473 \mathrm{~K}$ is the extrapolation of our dataset to $P=0 \mathrm{GPa}$. Open squares and solid and dashed lines at other temperatures have been constructed from the data fitted at $1473 \mathrm{~K}$ (see text). Grey areas are the range of results obtained for olivine and published previously (Bollinger et al, 2014).

Fig. 7: Ratio between olivine and forsterite deformation strain rates vs. pressure for samples deformed together, in the same experiment, at $1373 \mathrm{~K}$ (black diamond), $1473 \mathrm{~K}$ (grey triangles), $1573 \mathrm{~K}$ (white squares) and $1673 \mathrm{~K}$ (grey circles). 
Fig. 8: Stress exponent $n$ vs. Fe content for olivine deforming in dislocation or dislocation-accommodate

560

561

562

563

564

565

566

567

568

569 GBS creep Black circles and open symbols are results for polycrystals and singe-crystals, respectively. Polycristalline data for Fe\#=0 are from this study, Relandeau, 1981 and Nishihara et al, 2014. Data at Fe\# =11\% are from Hirth and Kohlstedt, 2003 and Hansen et al., 2011, data for Fe\# 230\% are from Zhao et al. 2009, and data for Fe\# $=50 \%$ are from Hansen et al., 2012. Stress exponents for single crystals are from Darot and Gueguen (1981) with Fe\#=0, and from Bai et al. (1991 - their Table 1) with Fe\#=11\% in open symbols. Note that, despite different materials and run conditions, a clear trend - increasing $n$ with increasing Fe\# - can be observed. 


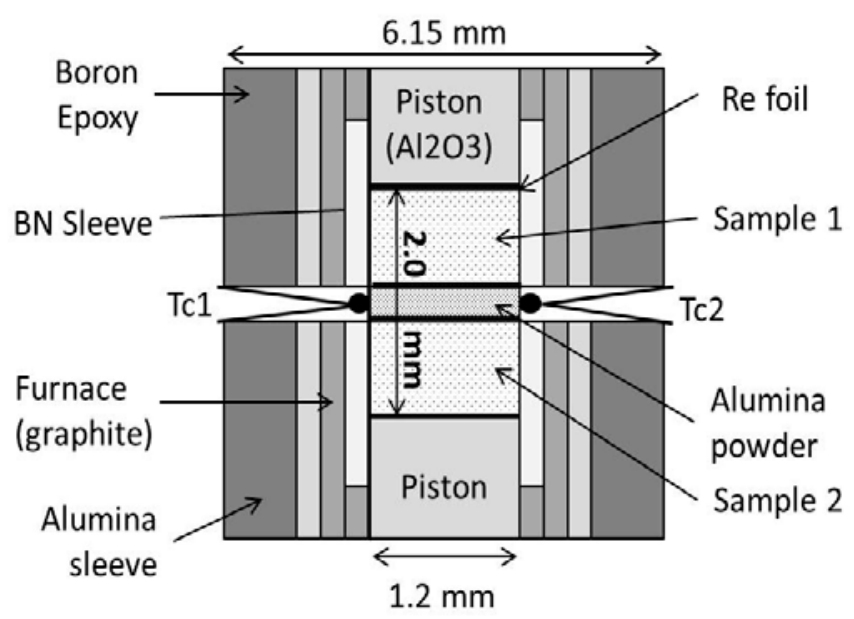

Fig. 1: Cross-section of the cell assembly used for the experiments. Olivine and forsterite samples, separated by an alumina buffer, are studied simultaneously. Tc1 and Tc2 are thermocouples in contact with the alumina. Re foils are used to monitor samples strain using $x$-ray radiography. This paper focuses on forsterite rheology. Results regarding olivine rheology have been published in Bollinger et al. (2014).

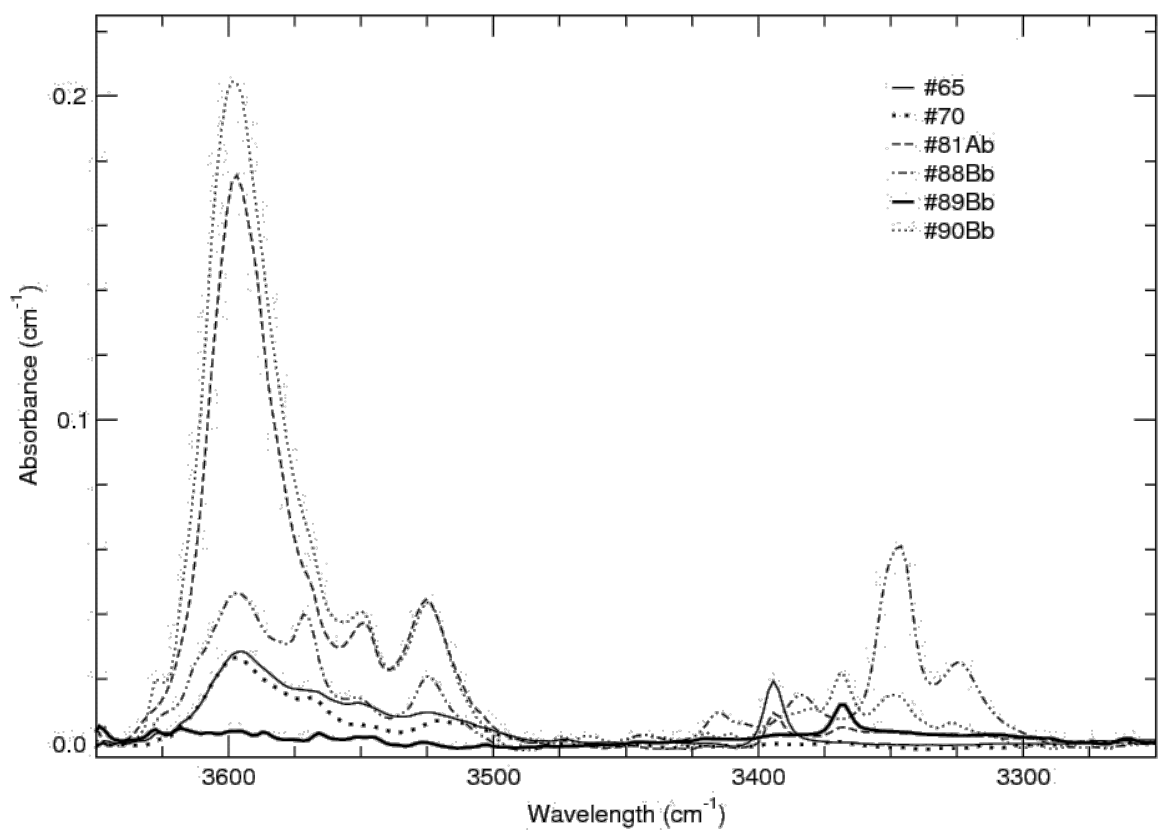

Fig 2: Unpolarized FTIR spectrum for forsterite run products, normalized to a 1-cm sample thickness, after manually subtracting the baseline. Some samples (e.g. run\# 65, 81, 88, 90) contain a substantial amount of water. Other samples (e.g. run 70,89) are less hydrated. In any cases, our samples are not dry and hence, treated as 'wet' forsterite. 

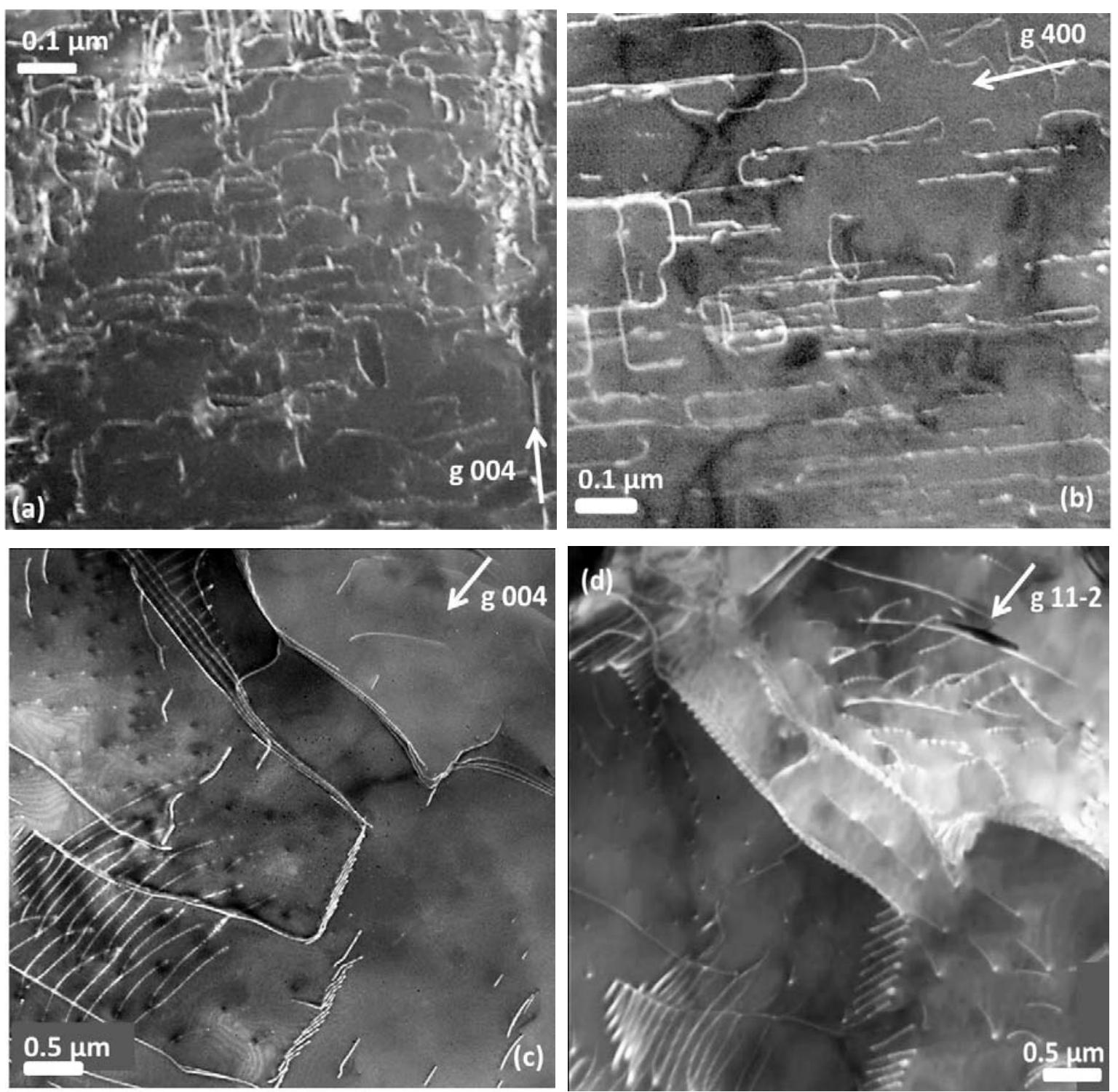

Fig. 3: TEM micrographs in Weak-Beam Dark Field (WBDF). (a) Sample \#65 (3-steps deformation experiment, $\sim 5 \mathrm{GPa}, 1373 \mathrm{~K})$. On this image performed with $\mathrm{g}: 004$, one can see free [001]-dislocations in glide configuration in (010) plane. (b) Sample \#65, g: 400; [100]-dislocations with their screw and edge components gliding in the (010) plane. (c) Sample \#88B ( 7.3 GPa, 1473-1673 K); g: 004; [001]-dislocations. Many are involved in subgrain boundaries. (d) Same area with $g=11-2$. Both [100]- and [001]-dislocations are visible. 

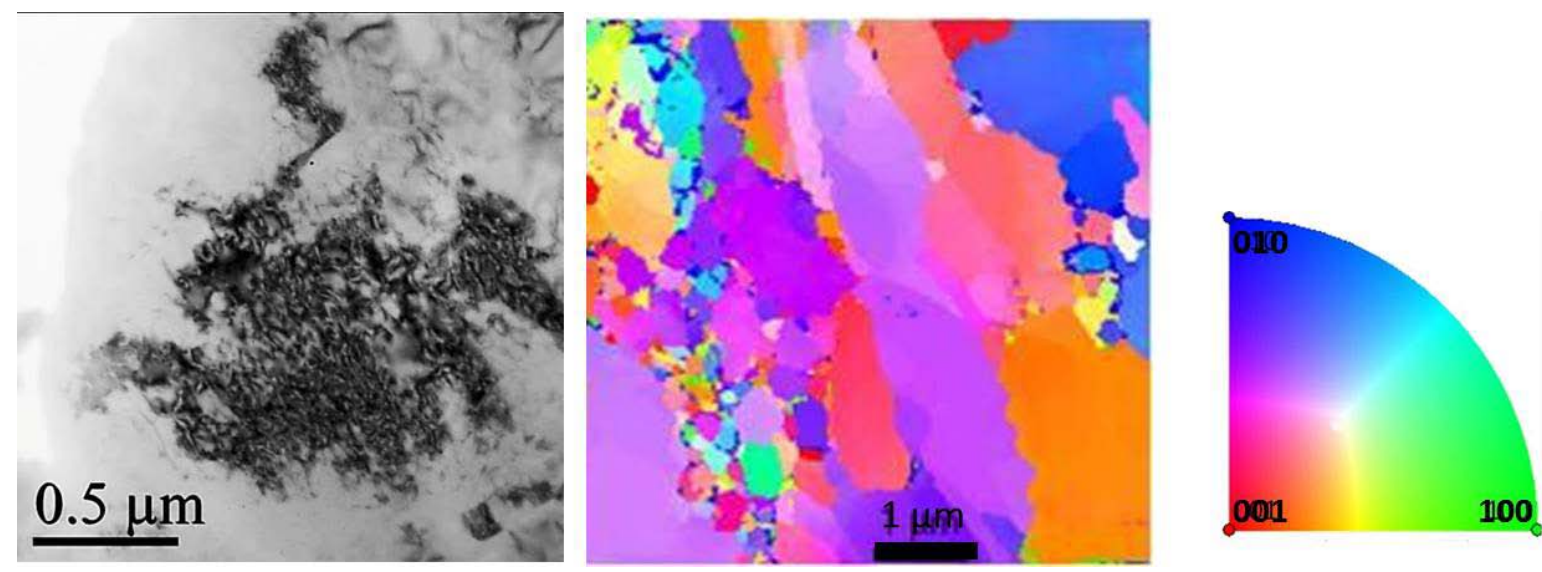

Fig. 4: a) Sample 70 (1373 K, $2.4 \mathrm{GPa}, 40 \%$ total deformation rate) observed in bright field. The high density of defects prevents observation of the microstructure, including grain sizes. b) Orientation map for sample 70 with corresponding color code, which is an inverse pole figure describing the crystal orientation perpendicular to the plane of view.

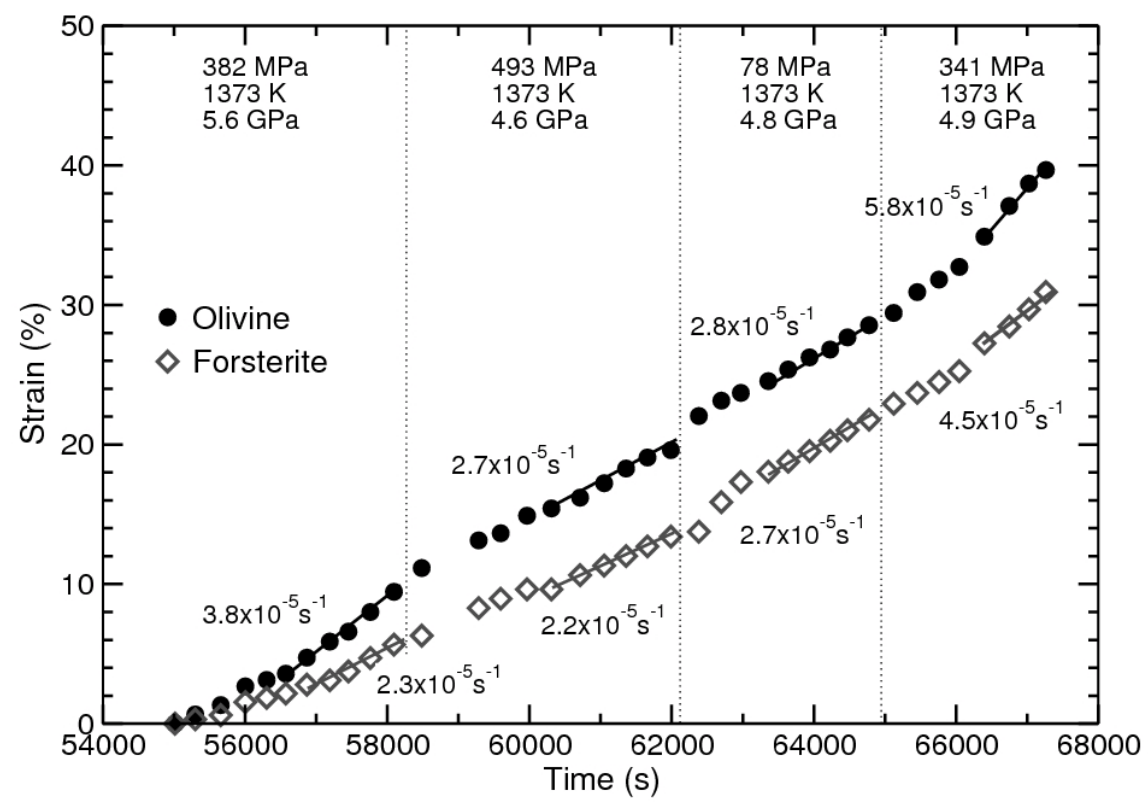

Fig. 5: Strain versus time for olivine (circle) and forsterite (squares) specimens deformed simultaneously during Run \#81 under the same conditions of $P, T$, and $\sigma$. Solid lines are linear fit through the data for extracting the steady-state strain rates, indicated in the figure. Note that strains in forsterite are lower than those in olivine, indicating the larger strength of forsterite relative to that of olivine. Also note that the olivine strain-rate sensitivity to stress is higher than that of forsterite (e.g. between steps 3 and 4). See text for further explanations. 

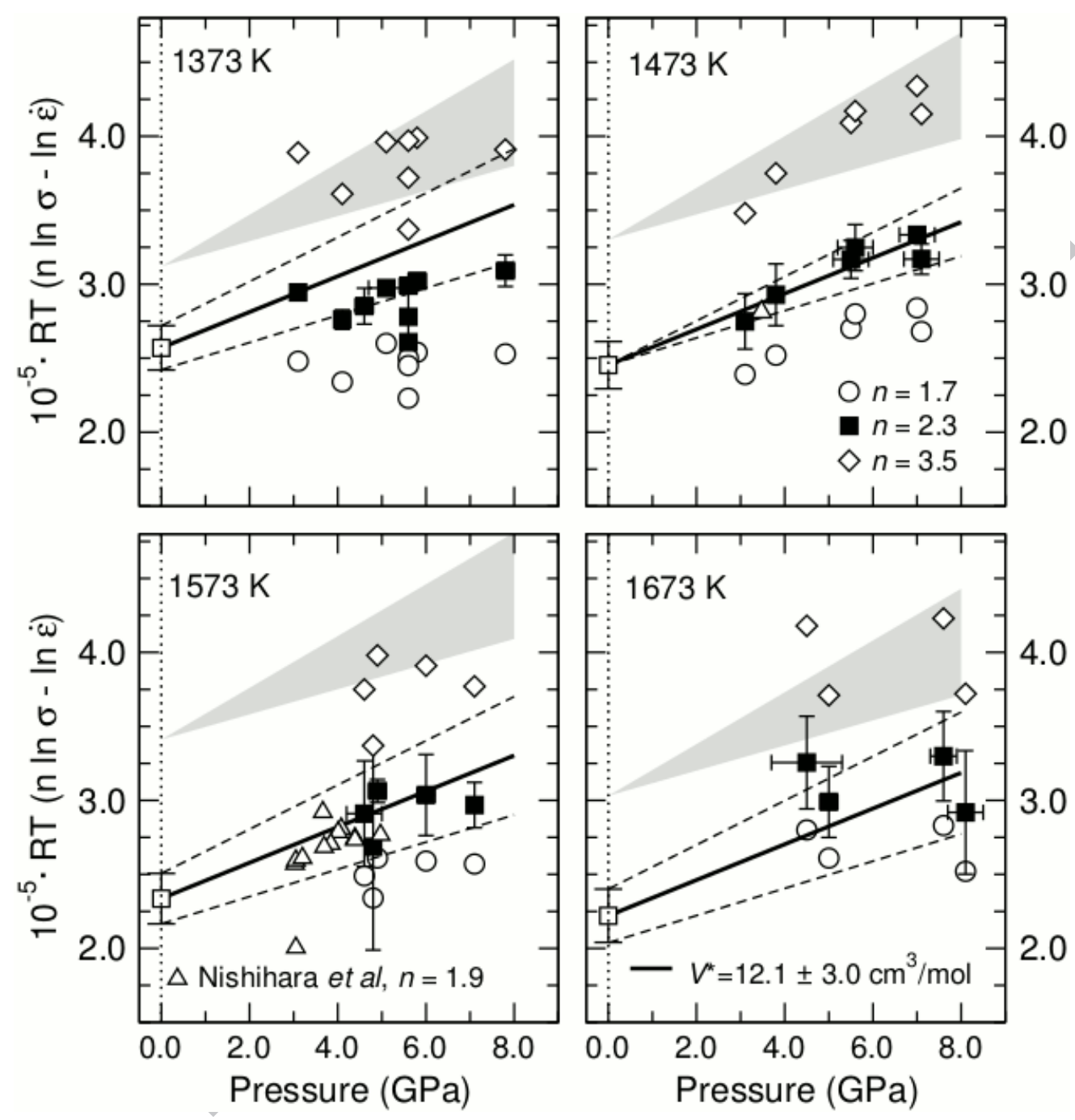

Fig 6: $\mathscr{H}^{P}{ }^{T}=R T(n \ln \sigma-\ln \dot{\varepsilon})$ vs. $P$ for wet forsterite polycrystals for the four experimental temperatures of this study $(1373,1473,1573$ and $1673 \mathrm{~K})$. Open circles, solid squares, and open diamonds are data from this study assuming $n_{F o}=1.7$ (McDonnell et al., 2000), $n_{F o}=2.3$ (this study), and $n_{F o}=3,5$ (olivine, Hirth and Kohlstedt, 2003). Open triangles are data from Nishihara et al (2014), assuming $n_{F o}=1.9$. Solid and dashed lines at $1473 \mathrm{~K}$ is a fit to our data, assuming $n_{F o}=2.3$, and leading to $V^{*}=12.1 \pm 3.0 \mathrm{~cm}^{3} \cdot \mathrm{mol}^{1}$. Open square at $1473 \mathrm{~K}$ is the extrapolation of our dataset to $P=0 \mathrm{GPa}$. Open squares and solid and dashed lines at other temperatures have been constructed from the data fitted at $1473 \mathrm{~K}$ (see text). Grey areas are the range of results obtained for olivine and published previously (Bollinger et al, 2014). 


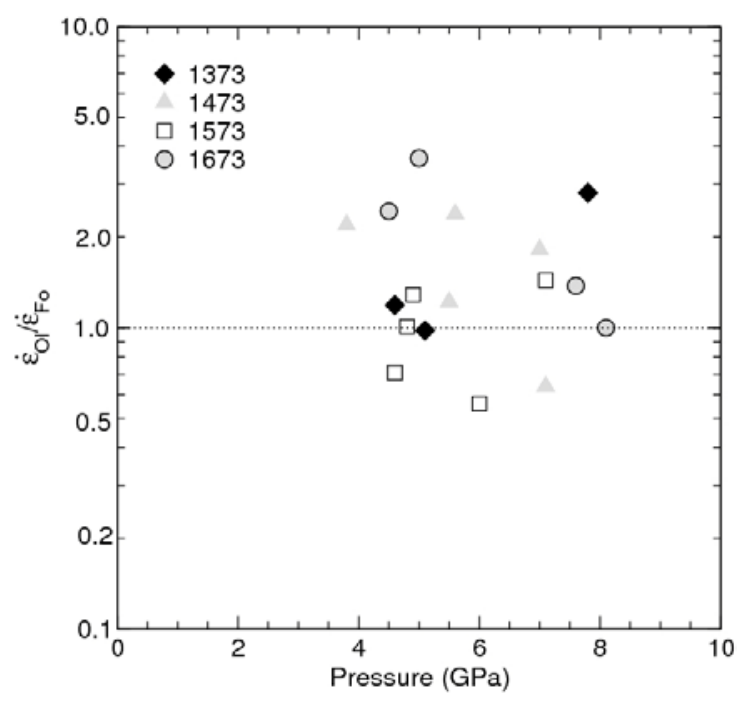

Fig. 7: Ratio between olivine and forsterite deformation strain rates vs. pressure for samples deformed together, in the same experiment, at $1373 \mathrm{~K}$ (black diamond), $1473 \mathrm{~K}$ (grey triangles), $1573 \mathrm{~K}$ (white squares) and $1673 \mathrm{~K}$ (grey circles).

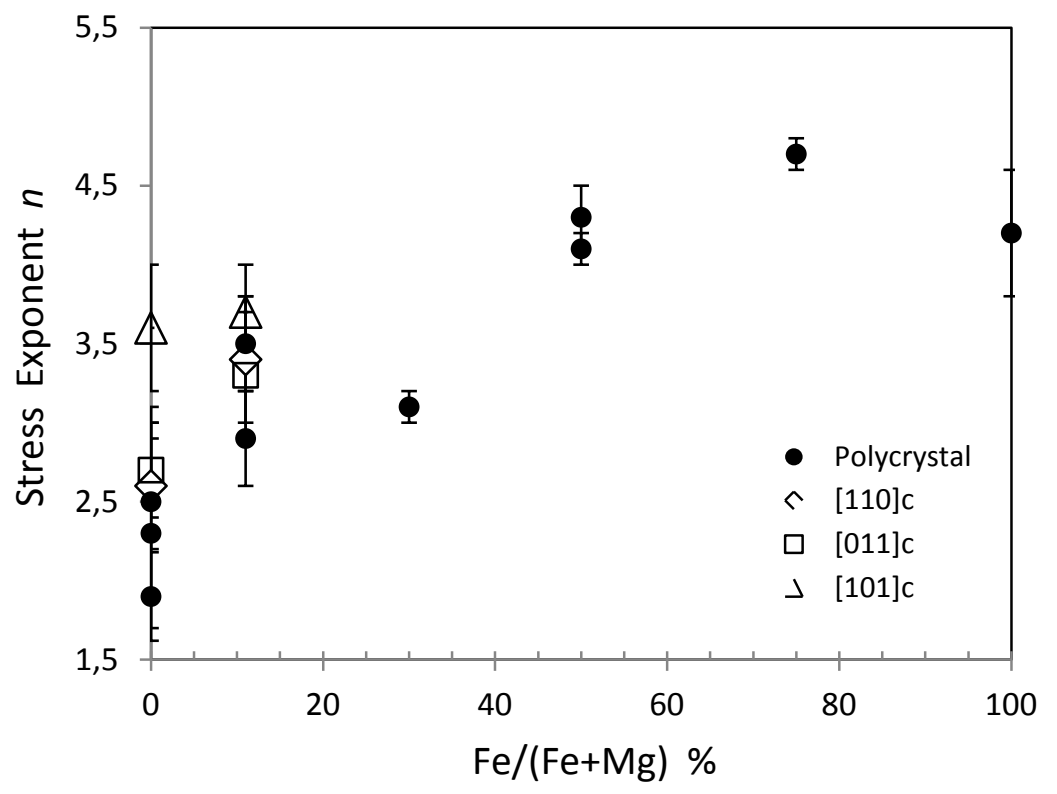

Fig. 8: Stress exponent $n$ vs. Fe content for olivine deforming in dislocation or dislocation-accommodate GBS creep Black circles and open symbols are results for polycrystals and singe-crystals, respectively. Polycristalline data for Fe\#=0 are from this study, Relandeau, 1981 and Nishihara et al, 2014. Data at Fe\# $=11 \%$ are from Hirth and Kohlstedt, 2003 and Hansen et al., 2011, data for Fe\# $\geq 30 \%$ are from Zhao et al. 2009, and data for $\mathrm{FeH}=50 \%$ are from Hansen et al., 2012. Stress exponents for single crystals are from Darot and Gueguen (1981)

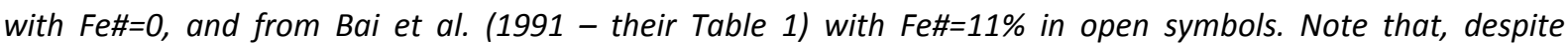
different materials and run conditions, a clear trend - increasing $n$ with increasing Fe\# - can be observed. 
Table 1: Steady-state conditions of deformation and $[\mathrm{OH}]$ contents in the run products

\begin{tabular}{|c|c|c|c|c|c|c|c|c|c|c|c|c|c|c|c|}
\hline \multirow{2}{*}{ Run \# } & \multirow{2}{*}{ Def. } & \multirow{2}{*}{$\begin{array}{c}T \\
(\mathrm{~K})\end{array}$} & \multirow{2}{*}{$\begin{array}{c}\dot{\varepsilon} \\
\left(10^{-5} s^{-1}\right)\end{array}$} & \multicolumn{3}{|c|}{$\sigma(\mathrm{MPa})^{*}$} & \multicolumn{4}{|c|}{$P(\mathrm{GPa})^{*}$} & \multicolumn{3}{|c|}{ Paterson (1982) } & \multicolumn{2}{|c|}{ Bell et al. (2003) } \\
\hline & & & & Top & Btm & Mean & Top & $\mathrm{Btm}$ & Mean & Fo & Abs. $\left(\mathrm{cm}^{-2}\right)$ & $\mathrm{ppm} / \mathrm{H}_{2} \mathrm{O}$ & $\mathrm{H} / 10^{6} \mathrm{Si}$ & $\mathrm{ppm} / \mathrm{H}_{2} \mathrm{O}$ & $\mathrm{H} / 10^{6} \mathrm{Si}$ \\
\hline \multirow[t]{3}{*}{65} & Axial & 1373 & $3.8(0.07)$ & $1109(81)$ & $1284(217)$ & $1196(115)$ & $5.2(0.2)$ & $6.3(0.2)$ & $5.8(0.2)$ & $5.9(0.1)$ & 130 & 32 & 531 & 73 & 1224 \\
\hline & Lateral & 1373 & $2.4(0.05)$ & $-809(78)$ & $-465(87)$ & $-637(210)$ & $4.4(0.2)$ & $5.9(0.2)$ & $5.2(0.2)$ & $5.7(0.1)$ & & & & & \\
\hline & Axial & 1373 & $5.5(0.06)$ & $1157(185)$ & $1327(313)$ & $1242(123)$ & $5.3(0.2)$ & $5.8(0.2)$ & $5.6(0.2)$ & $5.9(0.1)$ & & & & & \\
\hline 68 & Axial & 1373 & $4.8(0.05)$ & $592(355)$ & $386(200)$ & 489 (122) & $4.4(0.1)$ & $3.8(0.1)$ & $4.1(0.1)$ & $3.5(0.1)$ & & & & & \\
\hline 69 & Axial & 1373 & $4.4(0.06)$ & $230(122)$ & 295 (167) & $263(48)$ & $5.7(0.1)$ & $5.5(0.1)$ & $5.6(0.1)$ & $5.5(0.1)$ & & & & & \\
\hline 70 & Axial & 1373 & $4.5(0.17)$ & 965 (97) & $953(143)$ & 959 (56) & $3.7(0.2)$ & $2.4(0.1)$ & $3.1(0.1)$ & $2.4(0.1)$ & 40 & 10 & 175 & 22 & 375 \\
\hline 79 & Axial & 1473 & $1.7(0.35)$ & $93(114)$ & $198(123)$ & $146(96)$ & $3.0(0.1)$ & $3.2(0.1)$ & $3.1(0.1)$ & $3.5(0.1)$ & & & & & \\
\hline 80 & Axial & 1473 & $1.5(0.17)$ & $125(156)$ & 399 (129) & 262 (194) & $3.1(0.1)$ & $4.6(0.1)$ & $3.8(0.1)$ & $2.7(0.1)$ & & & & & \\
\hline \multirow[t]{4}{*}{81} & Axial & 1373 & $2.3(0.20)$ & $593(198)$ & $170(62)$ & 382 (315) & $6.2(0.2)$ & $4.9(0.1)$ & $5.6(0.2)$ & - & 400 & 106 & 1777 & 226 & 3769 \\
\hline & Axial & 1373 & $2.2(0.03)$ & $653(105)$ & $333(88)$ & 493 (228) & $4.9(0.1)$ & $4.2(0.2)$ & $4.6(0.2)$ & $4.5(0.1)$ & & & & & \\
\hline & Axial & 1573 & $2.7(0.05)$ & 206 (99) & $-49(40)$ & $78(181)$ & $5.2(0.1)$ & $4.3(0.1)$ & $4.8(0.1)$ & $4.1(0.1)$ & & & & & \\
\hline & Axial & 1573 & $4.5(0.20)$ & $341(88)$ & - & 341 (88) & $4.9(0.2)$ & - & $4.9(0.2)$ & $3.4(0.1)$ & & & & & \\
\hline \multirow[t]{2}{*}{82} & Axial & 1373 & $0.9(0.05)$ & $545(264)$ & 1116 (137) & 831 (337) & $8.1(0.1)$ & $7.5(0.2)$ & $7.8(0.2)$ & $8.1(0.1)$ & & & & & \\
\hline & Axial & 1573 & $1.7(0.01)$ & - & $163(83)$ & $163(83)$ & - & $7.1(0.1)$ & $7.1(0.1)$ & $6.4(0.1)$ & & & & & \\
\hline \multirow[t]{3}{*}{87} & Axial & 1373 & $1.9(0.06)$ & 701 (152) & 773 (214) & 737 (117) & $5.1(0.4)$ & $5.0(0.4)$ & $5.1(0.4)$ & $3.8(0.1)$ & & & & & \\
\hline & Axial & 1573 & $4.4(0.16)$ & $203(241)$ & - & $203(241)$ & $5.7(0.3)$ & $3.5(0.4)$ & $4.6(0.4)$ & $4.5(0.1)$ & & & & & \\
\hline & Axial & 1573 & $3.4(0.38)$ & $94(62)$ & 459 (164) & $276(251)$ & $6.0(0.2)$ & - & $6.0(0.2)$ & $3.2(0.1)$ & & & & & \\
\hline \multirow[t]{2}{*}{88} & Axial & 1473 & $0.9(0.05)$ & $921(164)$ & 847 (176) & $884(110)$ & $6.9(0.4)$ & $7.1(0.4)$ & $7.0(0.4)$ & $6.6(0.1)$ & 145 & 30 & 493 & 82 & 1371 \\
\hline & Axial & 1673 & $2.0(0.43)$ & $103(100)$ & $442(174)$ & $272(256)$ & $8.3(0.3)$ & $6.9(0.3)$ & $7.6(0.3)$ & $4.9(0.1)$ & & & & & \\
\hline \multirow[t]{4}{*}{89} & Axial & 1473 & $1.1(0.03)$ & $363(115)$ & 706 (156) & 535 (244) & $5.3(0.4)$ & $5.7(0.4)$ & $5.5(0.4)$ & $4.9(0.1)$ & 52 & 7 & 110 & 30 & 493 \\
\hline & Axial & 1473 & $0.5(0.40)$ & $422(191)$ & 587 (190) & 504 (217) & $5.5(0.3)$ & $5.6(0.4)$ & $5.6(0.4)$ & $4.7(0.2)$ & & & & & \\
\hline & Axial & 1673 & $1.2(0.20)$ & $64(100)$ & 101 (96) & $83(62)$ & $5.1(0.2)$ & $4.9(0.2)$ & $5.0(0.2)$ & $3.6(0.1)$ & & & & & \\
\hline & Axial & 1673 & $2.2(0.40)$ & 95 (147) & 402 (126) & $248(242)$ & $4.7(1.2)$ & $4.2(0.4)$ & $4.5(0.8)$ & $3.3(0.1)$ & & & & & \\
\hline \multirow[t]{2}{*}{90} & Axial & 1473 & $2.7(0.02)$ & 608 (169) & 985 (170) & 796 (291) & $6.5(0.4)$ & $7.6(0.4)$ & $7.1(0.4)$ & $6.7(0.1)$ & 353 & 94 & 1565 & 199 & 3327 \\
\hline & Axial & 1673 & $4.5(0.01)$ & $64(100)$ & $172(80)$ & 118 (154) & $7.6(0.4)$ & $8.5(0.3)$ & $8.1(0.4)$ & $6.5(0.1)$ & & & & & \\
\hline
\end{tabular}

* $\sigma$ and $P$ were measured in the top (Top) and bottom (Btm) pistons and, for $P$, in forsterite (Fo) specimens as well. "Mean" indicates the average value. 
Table 2: Forsterite aggregate stress exponent determination (see text)

\begin{tabular}{|c|c|c|c|c|c|c|c|}
\hline Run \# & Step \# & $P(\mathrm{GPa})$ & $T(\mathrm{~K})$ & $\dot{\varepsilon}_{F o}\left(10^{-5} \mathrm{~s}^{-1}\right)$ & $\dot{\varepsilon}_{O l}\left(10^{-5} \mathrm{~s}^{-1}\right)$ & $n_{F o}$ & $\Delta n_{F o}$ \\
\hline \multirow[t]{4}{*}{81} & 1 & $5.6(0.2)$ & 1373 & $2.3(0.2)$ & $3.8(0.1)$ & & \\
\hline & 2 & $4.6(0.2)$ & 1373 & $2.2(0.1)$ & $2.7(0.1)$ & 0.46 & 0.90 \\
\hline & 3 & $4.8(0.1)$ & 1573 & $2.7(0.1)$ & $2.8(0.1)$ & & \\
\hline & 4 & $4.9(0.2)$ & 1573 & $4.5(0.2)$ & $5.8(0.2)$ & 2.46 & 0.27 \\
\hline \multirow[t]{4}{*}{89} & 1 & $5.5(0.4)$ & 1473 & $1.1(0.1)$ & $1.3(0.1)$ & & \\
\hline & 2 & $5.6(0.4)$ & 1473 & $0.5(0.4)$ & $1.1(0.2)$ & 16.52 & 25.60 \\
\hline & 3 & $5.0(0.2)$ & 1673 & $1.2(0.2)$ & $4.4(0.6)$ & & \\
\hline & 4 & $4.5(0.8)$ & 1673 & $2.2(0.4)$ & $5.3(0.1)$ & 11.40 & 9.62 \\
\hline \multicolumn{6}{|c|}{ weighted mean } & 2.3 & 0.6 \\
\hline
\end{tabular}

